\title{
Study of the economical and optimum thermal insulation thickness for buildings in a wet and hot tropical climate: Case of Cameroon
}

\author{
Modeste Kameni Nematchoua a,*, Chrysostôme R.R. Raminosoa ${ }^{\mathrm{b}}$, \\ Ramaroson Mamiharijaona ${ }^{c}$, Tchinda Renéd ${ }^{\mathrm{d}}$, José A. Orosa ${ }^{\mathrm{e}}$, Watis Elvis ${ }^{\mathrm{a}}$, Pierre Meukam ${ }^{\mathrm{f}}$ \\ a Environmental Energy Technologies Laboratory, University of Yaounde I, Cameroon \\ ${ }^{\mathrm{b}}$ Fluid and Energy Laboratory, University of Antsiranana, Madagascar \\ ${ }^{\mathrm{c}}$ Laboratory of Mechanics and Materials, University of Antsiranana, Madagascar \\ ${ }^{\mathrm{d}}$ LISIE, University Institute of Technology Fotso Victor University of Dschang, Cameroon \\ e Department of Energy and M. P. Escuela Técnica Superior de N. y M, University of A Coruña, Paseo de Ronda 51, 15011 A Coruña, Spain \\ ${ }^{\mathrm{f}}$ Laboratory of Energy, water and Environment, Polytechnic National School of Yaoundé, Cameroon
}

\section{A R T I C L E I N F O}

Article history:

Received 10 December 2014

Received in revised form

30 April 2015

Accepted 22 May 2015

Available online 11 June 2015

Keywords:

Energy savings

Economical and optimum

Thermal insulation thickness

Building

Tropical climate

\begin{abstract}
A B S T R A C T
In Cameroon, these last centuries, an increase in energy demand for cooling and heating in buildings has been witnessed all over the world. Solutions must be proposed by researchers and specialists of buildings to remedy this situation. In this study, a literature review on the thermal insulation applications to external walls of buildings was presented, and a case was investigated in a tropical wet and hot climate. The economic model including the cost of insulation material and the present value of energy consumption and the cost over a lifetime of 22 years of the building, were used to find the optimum insulation thickness, energy saving, and payback period, for buildings in Cameroon. Materials that extruded polystyrene were chosen and used for two typical wall structures (Concrete block (HCB) and compressed stabilized earth block wall (CSEB)). The yearly cooling transmission loads, according to wall orientations and percentage of radiation blocked were calculated using the explicit finite-difference method under steady periodic conditions. As a result, it was found that the lowest value of optimum insulation thickness $(0.09 \mathrm{~m})$ and energy savings $(79.80 \%)$ were obtained for the south-oriented wall, while the payback period (4.73years) was the highest on the same face compared to all wall orientations. Insulation optimum thickness was higher in the HCB wall $(0.0983 \mathrm{~m})$ than in CSEB wall $(0.0958 \mathrm{~m})$, however, the payback period was the weakest for the HCB wall compared to the other wall type.
\end{abstract}

c) 2015 Elsevier Ltd. All rights reserved.

\section{Contents}

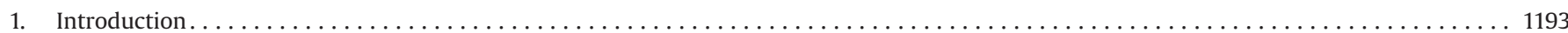

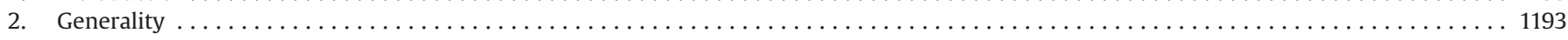

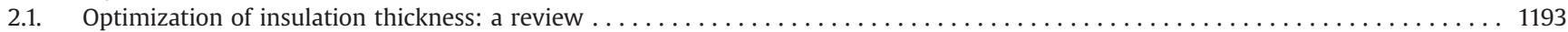

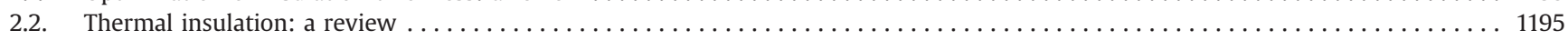

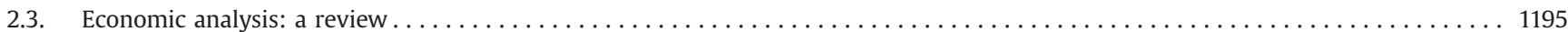

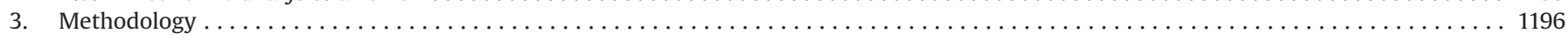

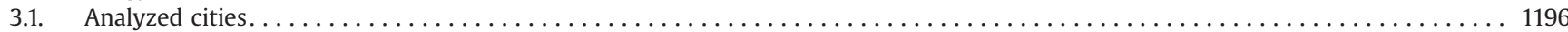

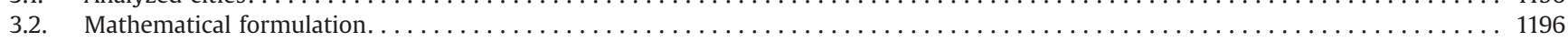

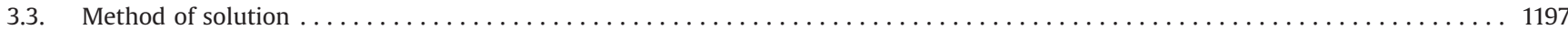

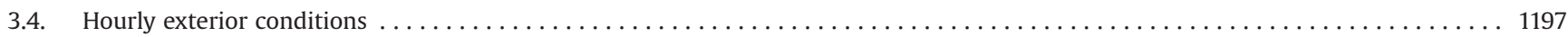

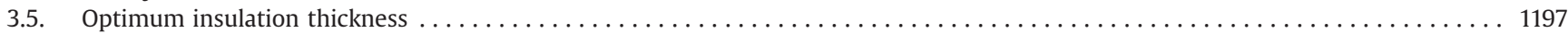

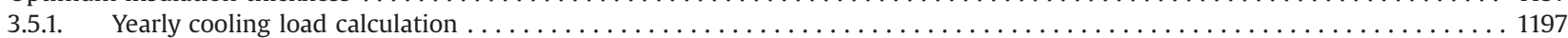

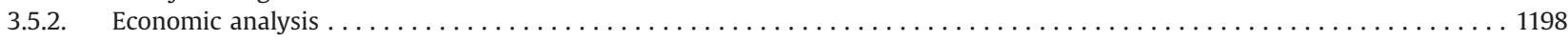

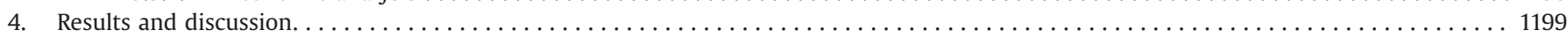

\footnotetext{
* Corresponding author.

E-mail address: kameni.modeste@yahoo.fr (M.K. Nematchoua).
} 


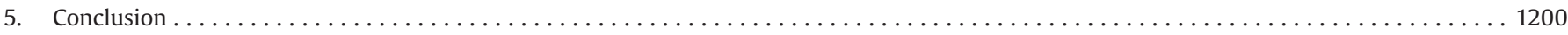

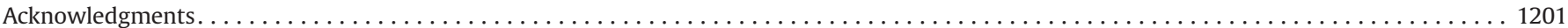

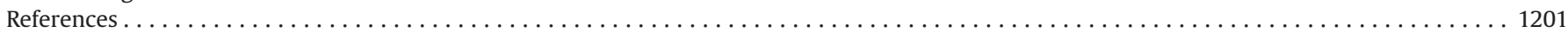

\section{Introduction}

A comfortable environment is necessary not only for health, but also for the productivity of the building's occupants [1,2]. Previous studies have showed that man spends a great part of his time inside buildings, to work, live or sleep [3,4]. Many countries use a combination of policy instruments to improve the energy efficiency in buildings, but all too frequently these policies are not aligned and fail to mutually reinforce each other. For example, in many countries, the energy requirements for buildings eligible for subsidies are not aligned, even in terms of the metrics used, with the energy requirements demanded by the building codes in force [5]. Higher energy prices (including energy taxes) increase the profitability of energy efficiency investments. However, studies in several countries have shown that the consumer response in the buildings sector, to higher energy prices, is relatively inelastic in the short term, that is, it is less than one - a $1 \%$ increase in household energy prices would lead to a decrease in the energy demand of between $0.1 \%$ and $0.4 \%$ [5]. One of the most efficient methods to reduce the transmission rate of heat and energy consumption to cool and heat buildings is the use of appropriated thermal insulation in the building envelope [6]. Architectural and physical properties of buildings, such as thermal mass, structural material, and its shape, are the most important parameters that influence the space-cooling load. During the last few decades, utilization of insulation materials has increased significantly, due, among other factors, to the ever-increasing values of insulation thickness imposed by national regulations [7]. An optimum thickness of insulation offers minimum total cost, including the cost of insulation and energy consumption on the life of the building [6]. The air-conditioning system (ACS) is responsible for a significant part of the total energy consumption in a building [8]. The capacity of ACS is determined according to the total cooling load of a building [8]. In Africa, energy consumption in modern and traditional buildings has increased considerably in recent years. A recent study on behavior by Kameni et al. [9] has proof that modern habitats in Cameroon are uncomfortable compared to traditional buildings, resulting in a great quantity of energy being consumed, for example, cooling energy in modern buildings. Many solutions can be suggested to improve energy consumption in these residences. Climate change has become the main preoccupation of the world, and attention has been drawn toward cooling energy [10]. More recently, the European Parliament has recommended that norm EN 832 (very similar to ISO 9164) be used for the calculation of the heating load, and that it be extended to that of the cooling load in buildings as well [10]. Nowadays, in Cameroonian cities, new buildings are seen more frequently, while the existing buildings are subject to major renovation. This directive demands consideration of the cost-optimal balance between the investment and the saved energy cost during the lifespan of a building. Several attractive studies on the thermal insulation have been carried out in different regions of world. But, however, these studies no really explained the necessity to use nowadays the insulation then of the building's conception, to reduce energy consumption. One of own characters of this work, compare to others study of same kind, was to select the local material cheaper, like a good thermal insulation.

The aim of the present study is to determine the optimum insulation thickness for an external concrete block wall and a compressed stabilized earth block wall, in hot tropical climate (Cameroon). Optimization was based on an economic model, in which the lifecycle cost analysis was conducted using one type of insulation material. The yearly cooling transmission loads, according to wall orientations, were calculated using the explicit finitedifference method under steady periodic conditions. In addition, the thermal performance of the walls, under optimal conditions, was also investigated.

\section{Generality}

\subsection{Optimization of insulation thickness: a review}

The performance of an insulated construction depends mainly on the thickness and the properties of the used insulation material [12]. However, this performance is subjected to various uncertainties related, for instance, to the manufacturing process of the material and to the different workmanship errors that affect the thermal resistance of the insulated construction [11]. In 2008, it has been shown that more than $50 \%$ of the consumed total energy in the building has been dedicated to heating and cooling [21]. This percentage is going to rise in the coming years, as the global population continues to increase [21]. Nowadays, many regulations are present, which prescribe values for the insulation thickness. However, there are no scientific articles that verify these values. Also, various heating systems may have different mechanisms of heat transfer, and therefore, the impact of insulation cannot be uniform [13]. Aïssani et al. [11] developed a new formulation of the global cost for the design of an insulation system, considering the additional costs related to user and environment. The proposed cost formulation allowed provision of a better estimation of the payback period. Three configurations were considered, with different insulation schemes in order to show the impact of uncertainties and indirect costs on the insulation performance. Farshid Bonakdar et al. [14] showed that the sustainability scenario could offer, approximately, 100\% increase in the optimum thickness of extra insulation compared to the Business As Usual scenario (BAU). However, the implication of different lifespans of 40,50 or 60 years, on the optimum measure appeared to be either negligible or very small, depending on the chosen scenario. Özden Ağra et al. [15] proved that when optimum insulation thickness was used, the energy consumption and the emission of carbon dioxide $\left(\mathrm{CO}_{2}\right)$ decreased. In addition, Ucar and Balo [16] calculated the optimum insulation thickness of the external wall, energy cost savings over a lifetime of 10 years, and payback periods for four different wall types in Elazığ. It was found that when optimum insulation thickness was used, the amount of fuel consumption and the emissions of $\mathrm{CO}_{2}$, sulfur dioxide $\left(\mathrm{SO}_{2}\right)$, nitrogen oxides ( $\mathrm{NOx}$ ), and carbon monoxide ( $\mathrm{CO}$ ) decreased, depending on the wall type. On the other hand, Naouel Daouas [6] made a life-cycle cost analysis of a building having a lifetime of 30 years, and the results showed that the south orientation was most economical with an optimum insulation thickness of $10.1 \mathrm{~cm}, 71.33 \%$ of energy savings, and a payback period of 3.29 years. It was noted that not only did wall orientation have a small effect on optimum insulation thickness, but a more significant effect on energy saving, which reached a maximum value of $23.78 \mathrm{TND} / \mathrm{m}^{2}$ in the case of an east facing wall. It also proved [6] that the economic parameters, such as, insulation cost, energy cost, inflation and discount rates, and lifetime of the 
building, had a noticeable effect on optimum insulation and energy savings. Fig. 1 shows a noticeable effect of wall orientation on the inside surface heat flux. In summer, one can note the highest peak for the west-facing wall, which receives an abundance of solar radiation in the early afternoon, when the sun is low in the horizon. In winter, the peak is the highest for the northfacing wall, which receives no direct solar radiation [6]. Subhash et al. [17] calculated the optimum insulation thickness and payback period for the different types of walls (brick, light weight concrete, and stone), as result, the optimum insulation thickness varied between $0.154 \mathrm{~m}$ and $0.1703 \mathrm{~m}$ and the payback period varied between 1.17 and 1.53 years, depending on the insulation material, external wall material, and climatic condition in India. In literature, an example of the optimum insulation thickness and payback period for various wall structures is given, which is shown in Table 1 [17]. Optimum insulation thickness varies between $0.154 \mathrm{~m}$ and $0.1703 \mathrm{~m}$ for glass wool, depending on the type of wall construction material [17]. Bojic and Loveday [18] used deterministic input variables to find the thermal performance of different arrangements, types, and thicknesses of insulation materials in buildings. Moghimi et al. [19] analyzed the energy performance of a hospital in the equatorial regions. The hospital was working $24 \mathrm{~h}$ per day, seven days a week, and 365 days a year. The result of optimum thickness of insulation and net saving
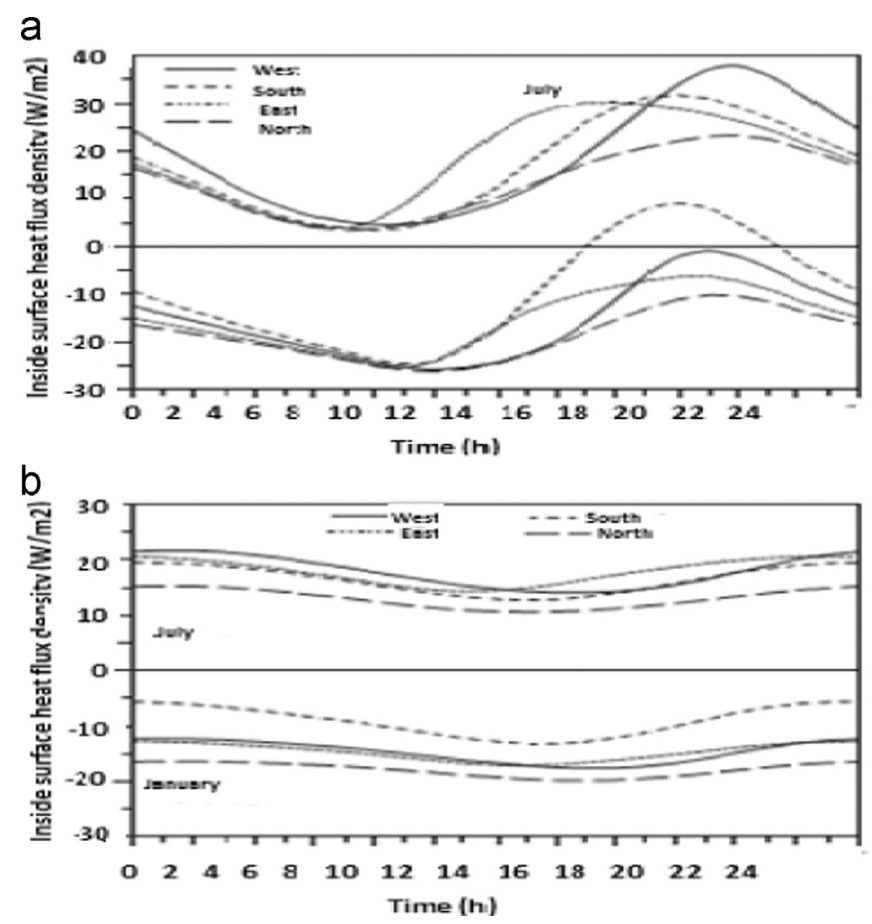

Fig. 1. Effect of wall orientation on the hourly variation of the inside surface heat flux density in cold and hot seasons for two wall structures: (a) $2.5 \mathrm{~cm}$ plaster $+15 \mathrm{~cm}$ brick $+2.5 \mathrm{~cm}$ plaster. (b) $2.5 \mathrm{~cm}$ plaster $+40 \mathrm{~cm}$ stone $+2.5 \mathrm{~cm}$ plaster [6].

Table 1

Optimum insulation thickness for various walls structures [17].

\begin{tabular}{llll}
\hline Wall type & $\begin{array}{l}\text { Resistance } \\
\left(\mathrm{m}^{2} \mathrm{k} / \mathrm{W}\right)\end{array}$ & $\begin{array}{l}\text { Optimum insulation } \\
\text { thickness }(\mathrm{m}) \text { for Glass wool } \\
(\mathrm{GW})\end{array}$ & $\begin{array}{l}\text { Payback period (years) } \\
\text { for Glass wool (GW) }\end{array}$ \\
\hline $\begin{array}{lll}\text { Brick } \\
\text { Light }\end{array}$ & 0.586 & 0.162 & 1.293 \\
$\begin{array}{l}\text { weight } \\
\text { concrete }\end{array}$ & 0.802 & 0.154 & 1.530 \\
Stone & 0.373 & 0.170 & 1.173 \\
\hline
\end{tabular}

shows that by increasing the lifetime period, the optimum thickness of insulation grows. This means that the age of the insulation has a direct relation with the thickness of the insulation. The annual energy cost over the life.

Time is evaluated as follows [20]:

$C_{\mathrm{TE}}=C_{\mathrm{E}} \cdot E \cdot \frac{(g+1)^{n}-1}{g} \cdot(g+1)$

where $C_{\mathrm{E}}$ is the energy cost in $\mathrm{RM} / \mathrm{kWh}, E$ is total annual energy consumption in $\mathrm{kWh}$, and $g$ is the inflation ratio in percentage, $n$ is the number of year.

The total insulation cost and net energy cost saving are defined as [19]

$C_{\text {ins }}=C_{\mathrm{i}} \cdot A_{\mathrm{f}} \cdot X_{\text {ins }}$

$N S=\left(C_{\text {TEUN }}-C_{\text {TEins }}\right)-C_{\text {ins }}$

where $C_{\text {ins }}$ is the total cost of the insulation, $C_{\mathrm{i}}$ is the cost of insulation in RM per $\mathrm{m}^{3}, A_{\mathrm{f}}$ is the total insulated area in the external walls in $\mathrm{m}^{2}, X_{\mathrm{ins}}$ is the insulation thickness, and NS is the net energy cost saving in RM. $C_{\text {TEins }}$ is the annual energy cost and insulation over the life time. The optimum economic is the value that provides the minimum total life-cycle cost, as illustrated in Fig. 2 [21].

Overview, the thickness is a function of the following: the building type, function, shape, orientation, construction materials, climatic conditions, insulation material and cost, energy type and cost, and the type and efficiency of air-conditioning system [22-25]. Hasan [26] used the life-cycle cost analysis to determine optimum insulation thicknesses. The results showed that a 10 -year lifetime savings up to $21 \$ / \mathrm{m}^{2}$ of wall area was possible from rock wool and polystyrene insulation. He determined payback periods of 1-1.7 years for rock wool and 1.3-2.3 years for polystyrene insulation, depending on the type of wall structure. Others authors also used the degree-hours method and meteorological data to give the prediction of the optimum thickness of insulation [27-31]. Another interesting study done is the one by Zhou and Zhao [56] who analyzed the energy-saving effect of different building envelops. The results obtained in every region were compared with each other in the different climatic regions of China. They used energy simulation with the economic analysis to evaluate the optimum expanded polystyrene (EPS) insulation thickness in buildings. Ozel and Pihtili [32] have assessed the optimum location and distribution of insulation in a wall. An analysis was made of 12 different wall configurations, with different configurations of insulation layers. The optimum location of insulation for the configurations analyzed was obtained from taking into

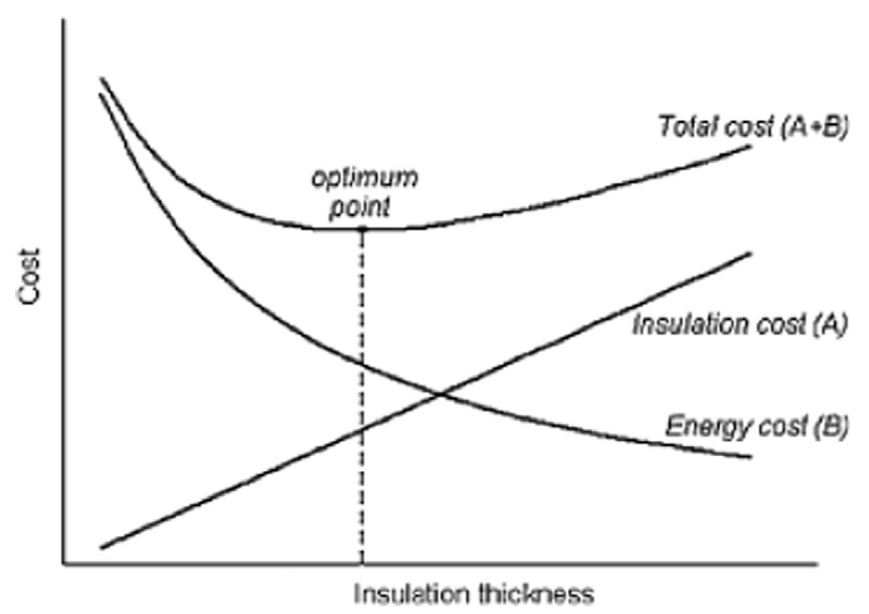

Fig. 2. Optimum insulation thickness [21]. 
consideration the time lag and decrement factor for various wall orientations. The results showed that the best thermal performance was obtained in the case where one of the three equal pieces of insulation layers was placed in the external surface of wall. By using the heating degree days (HDDs) and cooling degree days (CDDs), the annual Heating and cooling transmission loads could be estimated [21]. The variation in these loads and the decreasing ratio of the total annual transmission load with the insulation thickness are shown in Fig. 3. Cenk Onan [33] has investigated the existing building stock in Turkey depending on parameters such as height and area. A model building has been created covering all of these buildings. Fuel emission reduction of the combustion system was calculated for the insulation applied to this model building. The results showed that the optimum insulation thicknesses varied between 3.21 and $7.12 \mathrm{~cm}$, the energy savings varied between $9.23 \mathrm{US} \$ / \mathrm{m}^{2}$ and $43.95 \mathrm{US} \$ / \mathrm{m}^{2}$, and the payback periods varied between 1 and 8.8 years, depending on the regions. In addition, when the optimum insulation thickness was applied in the model building, the total energy savings for the country were calculated to be 41.7 billion US\$. Also total $\mathrm{CO}_{2}$ emissions for the country were calculated to be 57.2 billion $\mathrm{kg} \mathrm{CO}_{2}$ per year after insulation. Some works concerning thermal insulation are given above.

\subsection{Thermal insulation: a review}

The power of the insulation materials is mainly determined by its thermal conductivity, which is dependent on the density, porosity, moisture content, and also the mean temperature difference of the material [57]. Thermal insulators play a big role in preventing losses of heat. For all materials, thermal conductivity varied with operating temperature. A larger temperature gradient results in higher thermal conductivity [58-59]. Polyurethane and polystyrene had the lowest rate of change in thermal conductivity while polyethylene and wood wool had much greater rates of change [21]. Energy conservation has become major task to satisfy the energy need of world. Different methods are tried for conservation of energy [54]. One of the most important factors to be considered in the design of energy-efficient buildings is the thickness of the insulation to be applied to the building. Thermal insulation is known as the most effective way of building energy conservation for cooling and heating [34]. By reducing the rate of heat transfer, it can be installed on the external side [11]. Thermal insulation plays a critical role in determining the amount of insulation material required in walls. Many search have been carried out concerning thermal insulation, meanwhile, their results obtained varied function of study's place and insulation

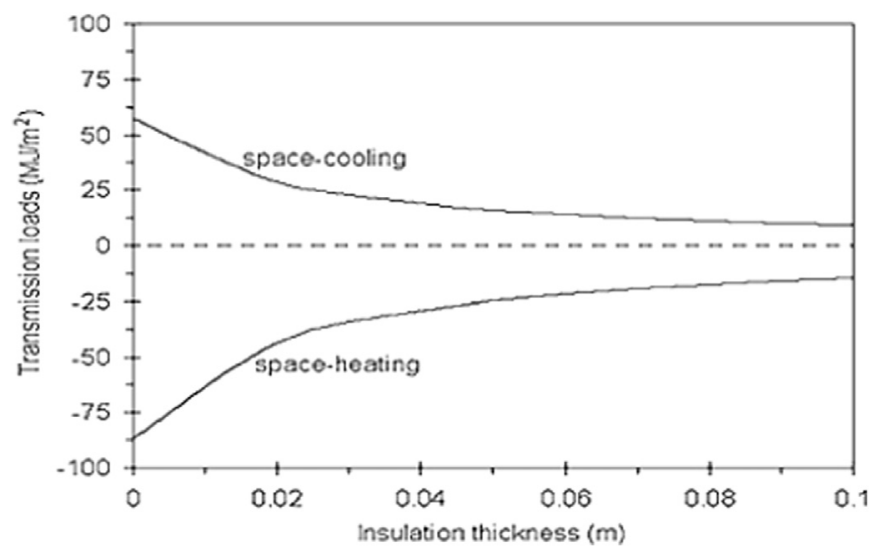

Fig. 3. The variation of annual heating and cooling transmission loads with insulation thickness [21]. materials selected [60-63]. A study carried out by Eben Saleh [35] showed that the utilization of thermal insulation allowed for significant improvement on the overall thermal performance of the buildings. Budaiwi et al. [59] studied some thermal characteristics of insulation materials(rock wool, polyethylene, etc.). Optimum thickness obtained during this study varied slightly according to insulation material. In using different insulation materials, Mahlia et al. [64] have succeeded to find relationship between optimum thickness and thermal conductivity. Moreover, Homoud [65] showed the basic principles of thermal insulation and their performance. This study has also been significant in locating thermal insulation within the outer side of the building envelope. Internal insulation requires approximately 50\% less investment cost than the external insulation, thus resulting in a lower payback period [36]. The optimum insulation thickness depends mainly on the cost of insulation material, cost of energy, yearly heating and cooling transmission loads, efficiency of the heating system, and coefficient of performance of the cooling equipment, building lifetime and inflation and interest rates.

\subsection{Economic analysis: a review}

The use of insulation on the external surfaces of the wall of a building needs additional investment. Overall, several financial methods are used to optimize the thermal insulation thickness of external walls. The most commonly used method is the Life Cycle Cost Analysis [37-39], which calculates the cost of a system or a component over its entire lifetime $\left(L_{\mathrm{T}}\right)$. The amount of net energy savings via insulation over a lifetime is evaluated in its present value using the Present Worth Factor (PWF), which depends on the inflation rate $i_{\mathrm{r}}$ and the discount rate $d_{\mathrm{r}}$, as follows [11]:

$\operatorname{PWF}=\left\{\begin{array}{cr}\left(\frac{1+i_{\mathrm{r}}}{d_{\mathrm{r}}-i_{\mathrm{r}}}\right)=\left[1-\left(\frac{1+i_{\mathrm{r}}}{1+d_{\mathrm{r}}}\right)^{L_{\mathrm{T}}}\right] & \text { for } i_{\mathrm{r}} \neq d_{\mathrm{r}} \\ \frac{L_{\mathrm{T}}}{1+d_{\mathrm{r}}} & \text { for } i_{\mathrm{r}}=d_{\mathrm{r}}\end{array}\right.$

$L_{\mathrm{T}}$ could be assumed to be 10 years $[40,41], 20$ years [ 42,43$]$, and so on.

The payback period is also another financial analysis model, which is the time required to recover the initial capital investment with the savings attributed to that investment [11].

Several studies used the $P_{1}-P_{2}$ method to calculate the net energy savings $[25,41,42,44,45] . P_{1}$ is the life cycle energy related to the market discount rate $d$ (for the value of money), the inflation rate $i$ (for the energy cost), and the economic analysis period. The value of $P_{1}$ can be calculated as follows [46]:

$P_{1}=\sum_{j=1}^{\mathrm{LT}} \frac{(1+i)^{j-1}}{(1+d)^{j}}=\left\{\begin{array}{cc}\frac{1}{(d-i)}\left[1-\left(\frac{1+i}{1+d}\right)^{L_{\mathrm{T}}}\right] & \text { if } i \neq d \\ \frac{\mathrm{LT}}{1+i} & \text { if } i=d\end{array}\right.$

$P_{2}$ is the ratio of the life cycle expenditures incurred because of the additional capital investment to the initial investment, which can be defined as [21]

$P_{2}=D+(1-D) P_{1}+M_{\mathrm{S}} P_{1}-\frac{R_{\mathrm{V}}}{(1+d)^{L_{\mathrm{T}}}}$

where $D$ is the ratio of the down payment to the initial investment, $M_{\mathrm{s}}$ is the ratio of the miscellaneous costs of the first year (maintenance, insurance, and other incidental costs) to the initial investment, and $R_{\mathrm{v}}$ is the ratio of the resale value at the end of the economic period to the initial investment. 


\section{Methodology}

\subsection{Analyzed cities}

The choice of Douala as the main investigation field city has not been made randomly. Douala is the Economic capital of Cameroon, the main business center and one of the largest cities in the country. The city is located along the Atlantic Ocean, between $4^{\circ} 03^{\prime} \mathrm{N}$ and $9^{\circ} 42^{\prime} \mathrm{E}$. With an area of nearly $210 \mathrm{~km}^{2}$, the climate of Douala is equatorial. It is characterized by temperatures between $18{ }^{\circ} \mathrm{C}$ and $34{ }^{\circ} \mathrm{C}$ with a mean around of $26^{\circ} \mathrm{C}$. A heavy precipitation, especially during the rainy season, from June to October. The air is almost constantly saturated. The relative humidity varied from $49 \%$ to $100 \%$, with a mean around of $62 \%$. The mean partial vapor pressure was between 2064 and 2609 Pa.Therefore, there is a 'relatively' dry season from October to May.

\subsection{Mathematical formulation}

Fig. 4 shows the concrete and earth blocks analyzed in this study.

To optimize the thickness of the insulation in the walls in modern homes, composite walls are considered (Fig. 5).

The outside face of the wall is subjected to variations in temperature $T_{\mathrm{o}}(t)$ and solar radiation $I(t)$. The inside face of wall comes in contact with the indoor air maintained at a fixed temperature of $T_{i}$ to have better thermal comfort. Each layer, $j$, of the composite wall, is therefore, the seat of a unidirectional transfer of heat in the supposed case was defined as [47]

$\rho_{j} c_{j} \frac{\partial T_{j}}{\partial t}=\lambda_{j} \frac{\partial^{2} T_{\mathrm{j}}}{\partial x^{2}}$

where $j$ refers to the serial number of the layer $(j=1, \ldots, \mathrm{M}$ for a wall of M layer); $x$ and $t$ are the spatial and temporal coordinates, respectively, $T_{j}$ is the temperature at the point of the coordinate $x$ in layer coordinate $j$ and $\rho_{j}, c_{j}$, and $\lambda_{j}$ are the density, specific heat, and thermal conductivity of the material of layer $j$, respectively. The resolution of Eq. (7) requires the determination of the boundary conditions and the initial condition. Thus, at the initial moment, we assume that all points of the wall have the same temperature $\left(25^{\circ} \mathrm{C}\right)$. The outside face conditions and indoor condition are given by following expressions:

$-\lambda_{1}\left(\frac{\partial T}{\partial x}\right)_{x_{1}=0}=h_{0}\left(T_{0}-T_{1}\right)+\alpha I$

$-\lambda_{\mathrm{M}}\left(\frac{\partial T}{\partial x}\right)_{x=L}=h_{\mathrm{i}}\left(T_{N}-T_{\mathrm{i}}\right)$

where $\alpha$ is the absorption coefficient and $h_{\mathrm{e}}$ and $h_{\mathrm{i}}$ are the thermal exchange coefficients on the outside and inside faces, respectively. Their values $\left(h_{\mathrm{e}}=22 \mathrm{~W} \mathrm{~m}^{-2} \mathrm{~K}^{-1}\right.$ and $\left.h_{\mathrm{i}}=9 \mathrm{~W} \mathrm{~m}^{-2} \mathrm{~K}^{-1}\right)$ have been obtained from a previous study [48]. I is the radiation of a

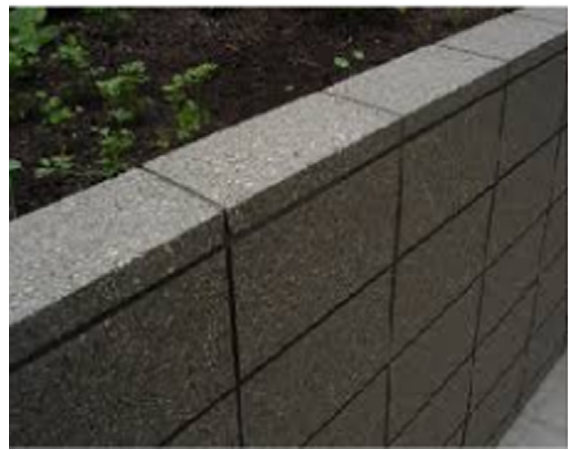

b

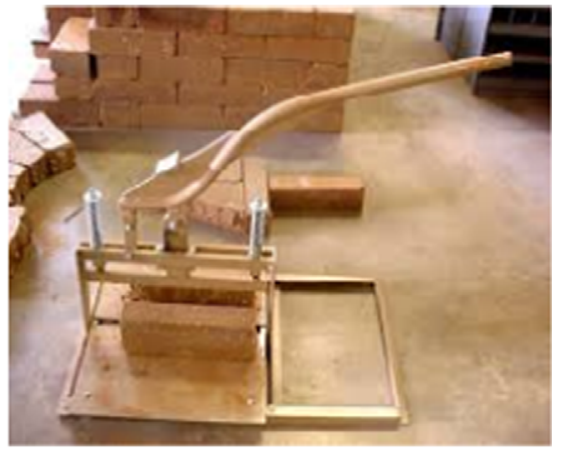

Fig. 4. Concrete block wall (a) and compressed stabilized earth block wall (b).

a

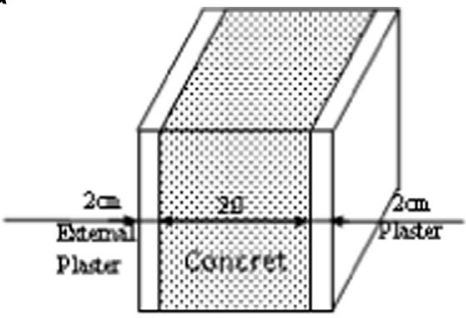

C

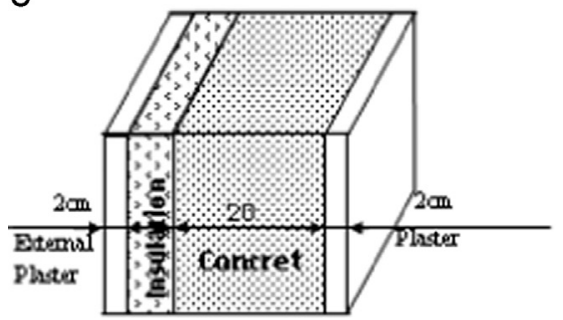

b

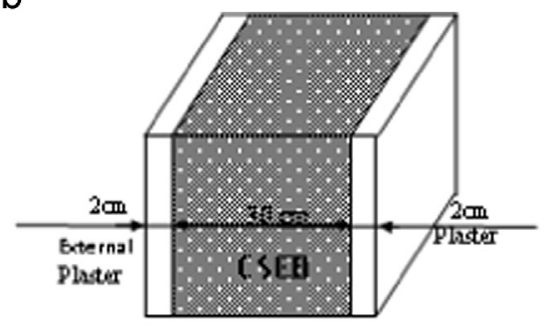

d

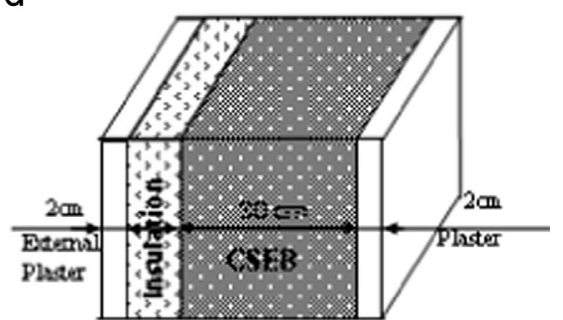

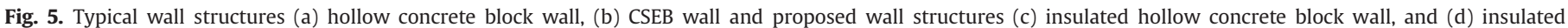
CSEB wall. 
the short wavelength received by the outdoor face wall (vertical), and is evaluated as follows [48]:

$I=I_{\mathrm{d}} R_{\mathrm{b}}+\frac{1}{2} \rho_{\mathrm{y}} I_{\mathrm{h}}+\frac{1}{2} D_{\mathrm{h}}$

where $I_{\mathrm{d}}, D_{\mathrm{h}}$ and $I_{\mathrm{h}}$ are the direct radiation, diffuse radiation and global radiation on a horizontal surface, respectively, and $\rho_{\mathrm{y}}$ is the albedo of the area, assumed to be equal to 0.2 . The parameter $R_{\mathrm{b}}$ is given for a vertical surface by [48]

$\mathrm{R}_{\mathrm{b}}=\frac{\cos \delta \sin \phi \cos \omega+\cos \delta \sin \gamma \sin \omega-\sin \delta \cos \phi \cos \gamma}{\cos \phi \cos \delta \cos \omega+\sin \phi \sin \delta}$

where $\delta, \omega, \gamma$, and $\phi$ are the solar declination, hourly angle, surface of the azimuth, and solar elevation, respectively. $\gamma$ is equal to 0 for an inclined surface facing south, 90 for a surface turned toward the east, 90 for a surface turned toward the west, and 180 for a north surface.

The third term of Eq. (10) designating the diffuse radiance on a vertical surface was obtained from a model developed in [49]. This model uses the simplifying hypothesis of a distribution isotrope of diffuse radiation that is independent of the zénithal and azimuthal angles. The thermophysical properties of the materials used are given in Table 2.

\subsection{Method of solution}

To solve the above-mentioned problem, a thermal model of an area consisting of a wall was constructed from the component library of Ham-tools, developed in the environment of MATLABSimulink simulation. The Ham-tools have been developed jointly by Chalmers University of Technology (Sweden) and the University of Technology in Denmark (Copenhagen, Denmark), and has been solved numerically using the Finite-Difference Method and a scheme of explicit temporal resolution (Eq. (7)).

For a stitch of thickness $d_{\mathrm{i}}$ inside the materials, the thermal balance at node i mesh center

Discrediting Eq. 7, we obtained

$\frac{\mathrm{T}_{i}^{n+1}-T_{i}^{n}}{\Delta t}=\frac{1}{\rho_{i} c_{i} d_{i}}\left(\frac{T_{i-1}^{n}-T_{i}^{n}}{R_{i-1}+R_{i}}+\frac{T_{i+1}^{n}-T_{i}^{n}}{\mathrm{R}_{i+1}+\mathrm{R}_{i}}\right)$

where $i$ denotes the number of nodes and $n$ indicates the time step. The resistances are defined as [48]

$R_{\mathrm{i}}=\frac{d_{\mathrm{i}}}{2 \lambda_{\mathrm{i}}}$

where $\lambda_{\mathrm{i}}$ is the thermal conductivity of the node material i. As the studied wall is composite, a node is placed at every interface between the two materials of different nature. The complete modeling of the heat transfer to the node of contact is given in [50].

The thermal balances are given by

$\frac{T_{1}^{n+1}-T_{1}^{n}}{\Delta t}=\frac{1}{\rho_{i} c_{i} d_{\text {out }}}\left(\frac{T_{2}^{n}-T_{1}^{n}}{R_{2}+R_{1}}+h_{0}\left(T_{\mathrm{o}}-T_{1}\right)+\alpha I\right)$

$\frac{T_{N}^{n+1}-T_{N}^{n}}{\Delta t}=\frac{1}{\rho_{i} c_{i} d_{\text {in }}}\left(\frac{T_{N-1}^{n}-T_{N}^{n}}{R_{N-1}+R_{N}}+h_{i}\left(T_{i}-T_{N}\right)\right)$

Table 2

Material properties.

\begin{tabular}{llcc}
\hline Materials & $\rho\left(\mathrm{kg} / \mathrm{m}^{3}\right)$ & $c(\mathrm{~J} / \mathrm{kg} / \mathrm{K})$ & $\lambda(W / m / K)$ \\
\hline Expanded polystyrene & 10 & 1400 & $0.03-0.06$ \\
Cement plaster & $2000-2300$ & 1050 & $0.80-0.95$ \\
Hollow concrete block & $1100-1400$ & 880 & $0.60-0.70$ \\
CSEB wall & $1700-1950$ & 1000 & $0.880-0.890$ \\
\hline
\end{tabular}

The numeric solution gives the temporal evolution of the temperature to every internal node of the wall and on the internal and external face of the wall. The density of the heat flux transmitted to the zone is obtained as follows [49]:

$q_{\mathrm{c}}(t)=\left\{\begin{array}{c}h_{\mathrm{i}}\left(T_{i}-T_{N}(t)\right) \quad \text { if } T_{i}>T_{N} \\ 0 \text { if } T_{i} \leq T_{N}\end{array}\right.$

The maximum step size of the time adopted in our model is an hour and the hourly exterior conditions are considered.

\subsection{Hourly exterior conditions}

The monthly averages of the minimum and daily maxima of temperature of every month for a relatively long period (19832005) were first calculated from the archives of the Department of Meteorology (Directorate of National Meteorology). These values were used to estimate the middle hourly values of temperature of every month from the model of cosine as follows [51]:

$T_{t}=\frac{T_{\max }-T_{\min }}{2} \cos \left(\frac{\pi(t-a)}{12}\right)+\frac{T_{\max }+T_{\min }}{2}$

where $T_{t}$ is the temperature at time $t(h)$ starting from midnight (in the range of 1-24); $T_{\max }$ and $T_{\min }$ are the minimum and maximum daily temperatures, respectively, and $a$ is the hour of the day at which the temperature is maximum. In the present study, the parameter $a$ was considered as 14 , as reported by Safeeq et al. [51,52].

The daily averages of the diffuse and global radiances on a horizontal surface, for every month, were obtained by dividing the number of days in the month considered, by the monthly averages of one relatively long period (1985-2005), which was obtained from [53]. The hourly averages of the diffuse and global radiances were obtained from the model of decomposition of Basunia et al. [54], considering the fifteenth day of the month as the representative day. Fig. 6, shows the monthly diurnal averages of temperatures and solar radiation levels in Douala. The outdoor temperature varied from $22.5{ }^{\circ} \mathrm{C}$ to $33.5{ }^{\circ} \mathrm{C}$ with a standard deviation (SD) of 0.66. A peak was obtained in February at around 1 p.m. The outdoor climate was the most favorable in August, with an average temperature of $25.4{ }^{\circ} \mathrm{C}$. From March, a light reduction in the air temperature was observed until the month of November, when the temperature appeared to increase. The global radiation was higher than $800 \mathrm{~W} / \mathrm{m}^{2}$ from January to February and lower than $600 \mathrm{~W} / \mathrm{m}^{2}$ from May to October. Direct normal radiation was $600 \mathrm{~W} / \mathrm{m}^{2}$ in January, while the diffuse radiation was around $300 \mathrm{~W} / \mathrm{m}^{2}$ for all the months, except in December where the value was very slow (Fig. 6). These different elements that were studied testified the unequal variation in the energies used for the cooling of the buildings in this region.

\subsection{Optimum insulation thickness}

The insulated wall reduces the yearly transmission load, which is the main input parameter of any optimum insulation thickness model.

\subsubsection{Yearly cooling load calculation}

The cooling period in the climatic zones under the field spread throughout the year or nearly the yearly quantity of energy $Q_{c}$ received by the indoor wall, was determined by integrating the values obtained for one year as the function $q_{\mathrm{c}}(t)$ given by Eq. (7). Yearly transmission loads was calculated based on the heat transfer model [6]. Fig. 7 shows the variation in the yearly cooling load with insulation thickness, in Douala, through the extruded polystyrene. The cooling transmission load is higher in the 


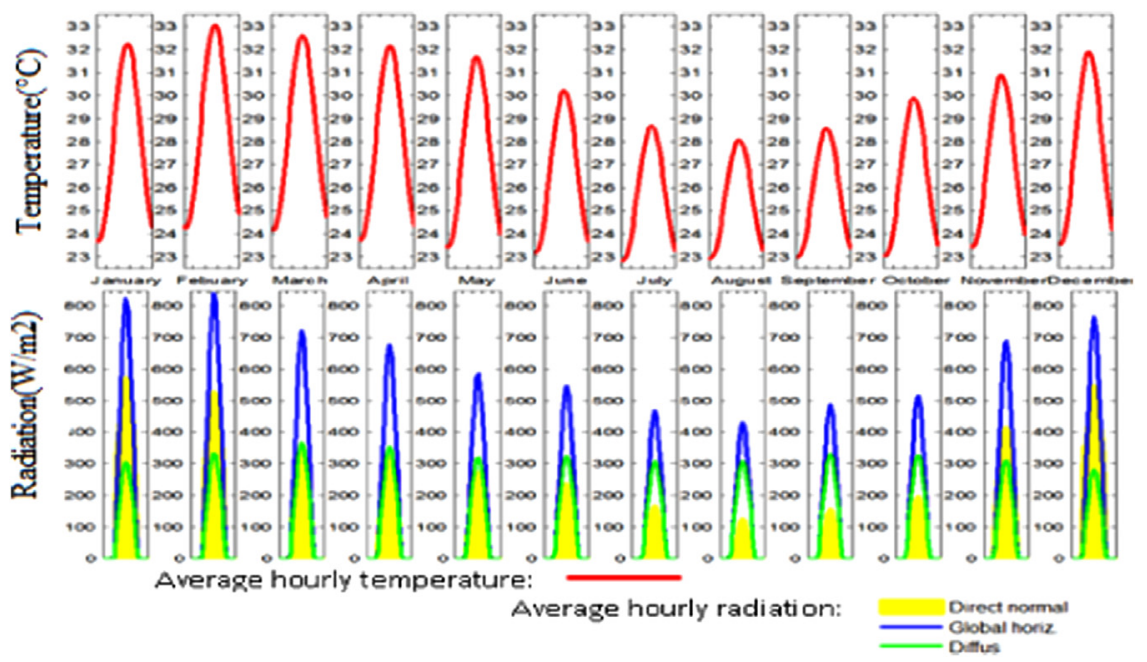

Fig. 6. Monthly diurnal averages of temperatures and solar radiation levels in Douala.

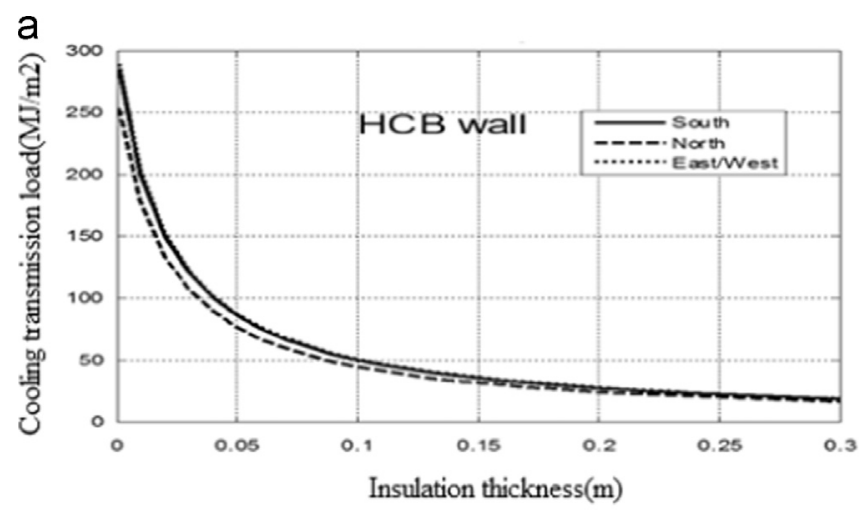

b

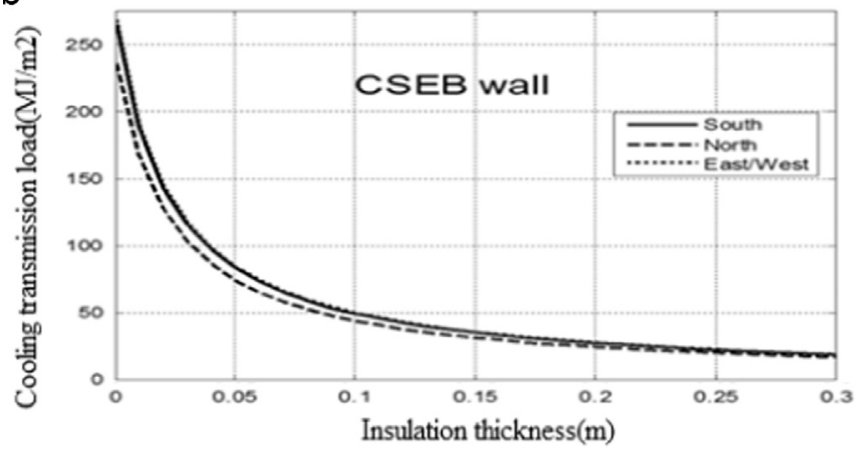

Fig. 7. Cooling transmission load versus insulation thickness for: (a) concrete block wall and (b) compressed stabilized earth block wall.

concrete block wall (Fig. 7a) than in the stabilized earth block wall (Fig. 7b). In this figure, it is seen that as the insulation thickness increases, the transmission loads decrease. However, this decrease is more rapid at smaller values of insulation thickness. The thermal gains through the East and West faces were practically equal and higher than those of the south and north faces. The thermal gains through the south face were slower, similar to the north face, because the zones of survey were in the northern hemisphere, where the north- and south-oriented walls received less solar energy than the walls of other orientations. Nevertheless, irrespective of the orientation of the wall, the yearly thermal gains decreased with the thickness of the insulator. The lowest cooling load was provided by the north-facing wall. Based on these results, it is recommended to insulate the east- and west-facing walls, to decrease the cooling energy in the buildings. These results are similar to those found in literature $[48,49,51,52]$ under different climatic conditions in the northern hemisphere.

\subsubsection{Economic analysis}

The installation of the insulator contributes to the reduction in the air-conditioning load and thus reduction in the electricity invoice. This reduction is especially important when the thickness of the insulator is large. However, to install an insulator, an initial investment is required, which increases with the thickness of the insulator. It is important to determine the insulator thickness that minimizes this total amount $\left(C_{\mathrm{t}}\right)$, which is equal to the sum of the present cost of the energy consumed during the time of existence of the building and the insulation cost [47].

$C_{\mathrm{t}}=C_{\mathrm{enr}} \mathrm{PWF}+C_{\mathrm{i}}=C_{\mathrm{enr}} \mathrm{PWF}+C_{\mathrm{ins}} L_{\mathrm{ins}}$

where $C_{\text {enr }}\left(\$ / \mathrm{m}^{2}\right.$ year) is the yearly cost of the electric energy consumed bound to the thermal gains through one square meter of wall; PWF is the 'present worth factor'; $C_{\mathrm{i}}\left(\$ / \mathrm{m}^{3}\right)$ is the cost of one cubic meter of insulator, and $L_{\mathrm{i}}(m)$ is the insulation thickness. $C_{(e n r)}$ depends on the yearly thermal gains through the unit wall surface $\left(Q_{c}\right)$, the price of an energy kilowatt-hour $\left(C_{\mathrm{el}}\right)$ and the coefficient of performance of the air-conditioning unit, as given by

$C_{\mathrm{enr}}=\frac{Q_{\mathrm{c}} C_{\mathrm{el}}}{\mathrm{COP}}$

PWF is a function of the interest rates and inflation, and is expressed as [48]

$\mathrm{PWF}=\sum_{u=1}^{n}\left(\frac{1+i}{1+d}\right)^{u}=\frac{1+i}{d-i}\left[1-\left(\frac{1+i}{1+d}\right)^{n}\right]$ si $i \neq d$

$\mathrm{PWF}=\frac{n}{1+i} \quad$ if $\quad i=g$

where $n$ is the yearly lifecycle of the building, $i$ is the currency inflation rate, and $d$ is the interest rate. The payback period is calculated by solving the following expression:

$\frac{C_{\mathrm{i}}}{A_{\mathrm{s}}}=\mathrm{PWF}$

where $C_{\mathrm{i}} / A_{\mathrm{S}}$ is the simple payback period that does not take the interest rate into account and $A_{S}$ is the amount of the annual savings obtained by insulation. 
The energy savings $\left(\$ / \mathrm{m}^{2}\right)$ obtained during the lifetime of the insulation material can be calculated as follows:

$\mathrm{ES}=C_{\mathrm{to}}-C_{\mathrm{tins}}$

where $C_{\text {to }}$ and $C_{\text {tins }}$ are the total cost of cooling without and with insulation, respectively. The energy saving can be expressed as a percent by the following equation:

$\frac{\mathrm{ES}}{C_{\mathrm{to}}} 100=\left(1-\frac{C_{\text {tins }}}{C_{\text {to }}}\right) 100$

The results obtained from the above-mentioned method can be compared with those of the degree-day method. In fact, the degree-day method has been used by several authors to estimate the optimal insulation thickness. In this method, the yearly transmission load per unit

of wall area is estimated (in $\mathrm{J} / \mathrm{m}^{2}$ ) by the following expression [48]:

$Q_{c}=86400 . U \cdot C D D$

where $\mathrm{CDD}$ is the annual cooling degree-day (in ${ }^{\circ} \mathrm{C}$ days). The value for the climate of Douala is 361. These values are calculated from the meteorological data (from the Directorate of National Meteorology) for a long period (20 years).

annual cooling degree-day can be obtained by the summation of the positive difference between the mean daily temperature and the fixed indoor base temperature $\left(25^{\circ} \mathrm{C}\right)$ over the whole year. The mean daily temperature can be calculated by adding the maximum and minimum temperatures for the day, and then dividing it by two.

The overall heat transfer coefficient of the wall can be expressed as follows [48]:

$U=\frac{1}{R_{\mathrm{o}}+R_{\mathrm{ins}}+R_{\mathrm{W}}+R_{\mathrm{i}}}$

where $R_{0}$ and $R_{\mathrm{i}}$ represent the heat resistance due to convective transfer on the outside and inside surfaces of the wall, respectively, and $R_{\text {ins }}$ and $R_{\mathrm{w}}$ represent the heat resistance of the insulation layer and rest of the wall, respectively.

The total cost (cost of energy and insulation) is given by [6]

$C_{\mathrm{t}}=\frac{0.024 \mathrm{CDD}}{\operatorname{COP}}\left(\frac{1}{R_{\mathrm{t}}+\frac{L_{\text {ins }}}{\lambda_{\text {ins }}}}\right) C_{\mathrm{el}} \mathrm{PWF}+C_{\mathrm{ins}} L_{\mathrm{ins}}$

where $L_{\text {ins }}$ and $\lambda_{\text {ins }}$ are the thickness and thermal conductivity of the insulating material, respectively.

$R_{\mathrm{t}}=R_{\mathrm{o}}+R_{\mathrm{W}}+R_{\mathrm{i}}$

The optimal insulation $L_{\mathrm{op}}$ is the thickness of the insulation layer that corresponds to that, minimizing the total cost [49].

$L_{\mathrm{op}}=\left(0.024 \frac{\mathrm{CDD} \lambda_{\text {ins }} C_{\mathrm{el}} \mathrm{PWF}}{C_{\text {ins }} \mathrm{COP}}\right)^{1 / 2}-\lambda_{\text {ins }} R_{\mathrm{t}}$

The parameters used in the calculation of the optimum insulating thickness are given in Table 3.

\section{Results and discussion}

The optimum insulation thickness is calculated by considering the sequential reduction in the cost of the consumed energy. However, the purchase and installation of the insulation layer, increase the initial cost of construction. Therefore, an economic analysis was performed in the present study to estimate the optimum insulation thickness, which minimizes the total cost, including the insulation and energy consumption costs. Fig. 8 shows

Table 3

The parameters used in the calculations $[13,14]$

\begin{tabular}{ll}
\hline Parameters & Values \\
\hline Electricity for cooling & \\
Cost $(\$ / \mathrm{kWh})$ & 0.1583 \\
COP & 2.5 \\
Expanded polystyrene cost $\left(\$ / \mathrm{m}^{3}\right)$ & 164.32 \\
Inflation rate, $I(\%)$ & 2.9 \\
Interest rate, $d(\%)$ & 5 \\
Life time, $n$ & 30 \\
\hline
\end{tabular}

\section{a}

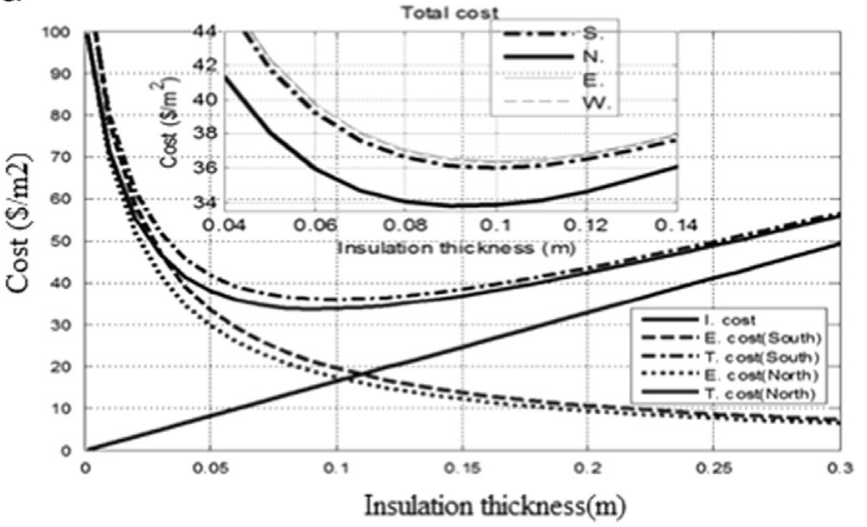

b

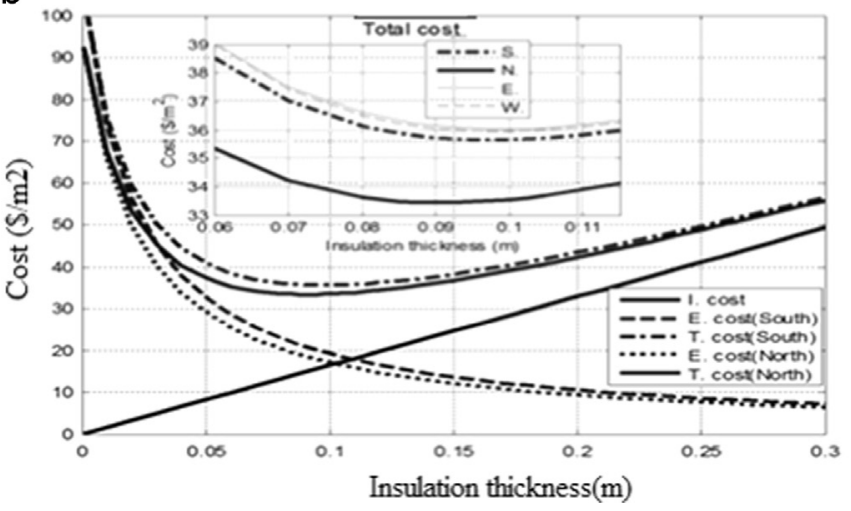

Fig. 8. Variations in insulation cost, electricity consumption cost, and total cost, with the insulation thickness applied on the: (a) concrete block wall and (b) compressed stabilized earth block wall.

Table 4

Optimum insulation thickness, annual energy savings, and payback period: effect of wall orientation and wall structure.

\begin{tabular}{|c|c|c|c|c|c|c|}
\hline Wall type & HCB & & & CSEB & & \\
\hline Orientation & North & South & East/West & North & South & East/west \\
\hline Optimum insulation thickness (m) & 0.1000 & 0.0925 & 0.1025 & 0.0975 & 0.0900 & 0.1000 \\
\hline Annual energy saving (\%) & 82.13 & 80.91 & 82.52 & 81.08 & 79.80 & 81.45 \\
\hline Payback period (years) & 4.20 & 4.44 & 4.19 & 4.48 & 4.73 & 4.48 \\
\hline
\end{tabular}


the insulation cost, energy cost, and total cost versus insulation thickness for different wall orientations. When the energy cost decreases with the increasing insulation thickness, the insulation cost increases linearly with insulation thickness. This can be explained by the fact that when the insulator transverse measurements are stationary, the cost is proportional to its thickness. These results have been in previous search proved by Mehmet [8], Dragan and Milorad [13]. The variations in the costs of electric energy according to the insulator thickness have the pace of those of thermal gains. Indeed, in the adopted economic model, these quantities are proportional. The total cost is the sum of the insulation and energy costs. The total cost function of the insulator thickness has a minimum value. The insulator thickness corresponding to this value constitutes the optimal thickness sought. The most economical cases with respect to the minimum total cost are the South and North orientations, followed by the East and West orientations, and this result is in conformity with those presented in literature by $[6,47,48]$. Nevertheless, the minimum total cost can vary according to the type of climate associated with the studied region. In the two types of walls (Figs. 8a and b), the total cost and energy cost consumed for cooling are very slow for the North and

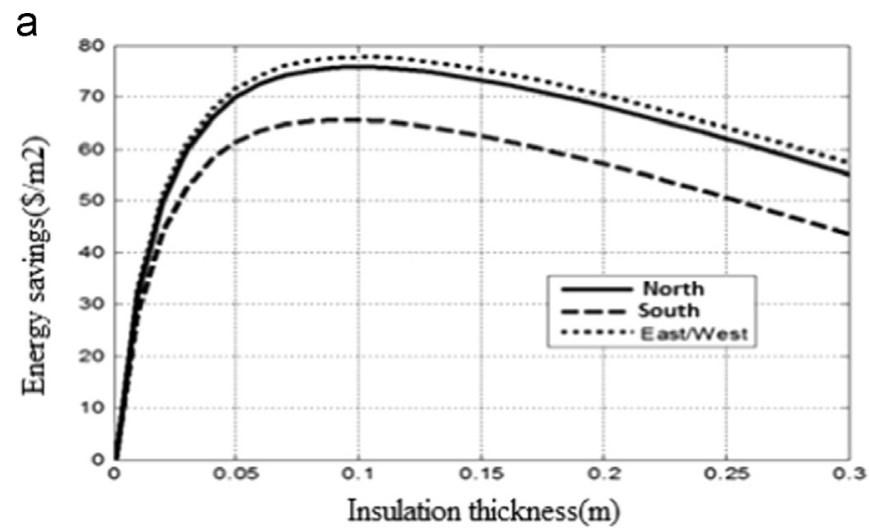

b

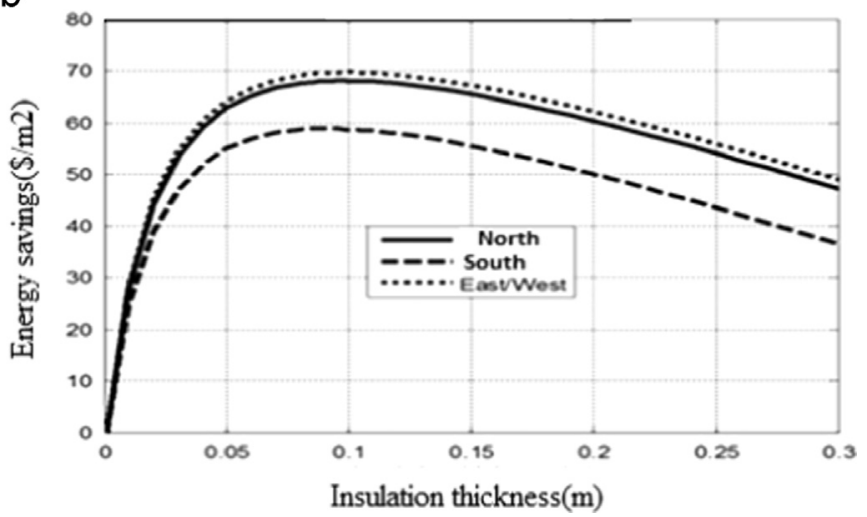

Fig. 9. Annual energy saving versus insulation thickness for: (a) HCB wall and (b) CSEB wall.
South orientations. These results are in agreement with those reported by Naouel Daouas [6].

Table 4 shows the insulator optimal thickness, the payback period on investment and energy savings according to the different orientations of the walls and climate of the city examined.

For the HCB, the optimum insulation thickness is $0.100 \mathrm{~m}$ for North orientation. It corresponds to an annual energy saving of $82.13 \%$ for 4.20 years, as payback period. However, for the same wall, the insulation optimum thickness is $0.102 \mathrm{~m}$ for the East/ West orientation. It corresponds to an annual energy saving of $82.52 \%$ for 4.19 years, as payback period. On the other hand, with the CSEB, the insulation optimum thickness is $0.097 \mathrm{~m}$ for the North orientation. It corresponds to an annual energy saving of 81.08\% for 4.48 years, as payback period. However, the optimum insulation thickness is $0.10 \mathrm{~m}$ for the East/West orientation, for an annual energy saving of $81.45 \%$. An analysis of these results shows that optimum insulation thickness is higher in the HCB wall than in the CSEB wall, however, the payback period is the weakest for the HCB wall compared to the other wall type. In this study, the optimum insulation thickness is greater, $34.88 \%$ and $25.23 \%$ for South and East wall orientation, respectively, compared to the results obtained by Ozel [48]. In contrast, these results are in good agreement with those obtained by references [27,42,45,55]. Fig. 9 shows the variation in energy savings versus insulation thickness for all wall orientations. The energy savings were maximum for an insulator thickness equal to its optimal value. Beyond this value, an increase in the insulator thickness resulted in a decrease in energy savings. It can be noted from these figures that the lowest value of energy savings was obtained for the South orientation wall, while the highest energy savings were obtained for the East/West walls. These findings are similar to those obtained in [6,47]. In both types of walls (HCB and CSEB), the energy saved is greater on the East/ West faces. A comparative study of different saved energies shows that the stabilized compressed earth block wall saves less than the concrete block wall (Table 5).

\section{Conclusion}

This study presented a literature review on the thermal insulation applications to external walls of buildings and an investigation case in the tropical wet and hot climate. In view of the high demand for moderate energy observed in recent years in modern buildings, many studies suggested solutions to reduce the annual energy consumption required to heat and/or cool buildings. Reducing the energy consumption in buildings is important because of limited energy resources and environmental concerns. A model was built using the MATLAB/Simulink, with the help of the International Building Physics Toolbox (IBPT) library, to determine a numerical solution of transient heat transfer through multilayer walls, submitted to the average outdoor temperature and solar radiation specific to the Douala climate. With this method, the inside surface heat flux of two common uninsulated walls (HCB and CSEB) was predicted. The results presented for the

Table 5

Comparative study of parameters obtained and those in the literature

\begin{tabular}{|c|c|c|c|c|}
\hline Paper & Economic method & Place & Opt. insulation thickness (m) & Insulation material \\
\hline Mahlia et al. [42] & $P_{1}-P_{2}$ & Malaysia & $0.040-0.100$ & Fiberglass-urethane \\
\hline Bolatturk [45] & $P_{1}-P_{2}$ & Turkey & $0.032-0.038$ & Extruded polystyrene board \\
\hline Yu et al. [25] & $P_{1}-P_{2}$ & China & $0.053-0.236$ & polyurethane, perlite, foamed \\
\hline Dombayci et al. [37] & LCC & Turkey & $0.032-0.138$ & Expanded polystyrene \\
\hline Daouas et al. [47] & LCC & Tunisia & Around of 0.057 & Expanded polystyrene \\
\hline This study & LCC & Cameroon & $0.092-0.102$ & Extruded polystyrene \\
\hline
\end{tabular}


representative day of the hottest month of the considered climate showed a significant effect of wall orientation on the thermal performance of the two walls. The model built using MATLAB/ Simulink was extended to determine the yearly cooling transmission load of the insulated wall. Similar to other studies, it was found that the energy cost decreases with increasing insulation thickness and the insulation cost increases linearly with insulation thickness. The optimum thickness varies depending on the material used and its association with the outdoor climate. The taking account of the results by the designer of the building is fundamental for the energetic efficiency of the building. The current results and conclusions, and in particular the relative performance of polystyrene, are dependent on the specific values of the parameters used in the thermal and economic analysis.

\section{Acknowledgments}

The authors thank the administration of the University of Yaoundé1 (Cameroon) and University of Antsiranana (Madagascar), as also the PAFROID (Partenariat inter-universitaire entre l'AFRique et l'Océan-Indien pour le Développement) project, for supporting this study.

\section{References}

[1] ASHRAE Standard 55. Thermal environment conditions for human occupancy, Atlanta, GA,USA; 2004.

[2] CIBSE. Environmental design, CIBSE Guide A. London: The Chartered Institution of Building Services Engineers; 1999.

[3] Hensen JLM. On the thermal interaction of building structure and heating and ventilating system. [PhD thesis]. Eindhoven: Technische University Eindhoven; 1991.

[4] Taylor P, Fuller RJ, Luther MB. Energy and thermal comfort in a rammed earth office building. Energy Build 2008:40:793-800.

[5] International Energy Agency. Mobilizing investment in energy efficiency: case studies in the residential sector. Information paper; 2012.

[6] Naouel D. A study on optimum insulation thickness in walls and energy savings in Tunisian buildings based on analytical calculation of cooling and heating transmission loads. Appl Energy 2011;88:156-64.

[7] Kolaitis Dionysios I, Malliotakis Emmanouil, Kontogeorgos Dimos A, Mandilaras Ioannis, Katsourinis Dimitrios I, Founti Maria A. Comparative assessment of internal and external thermal insulation systems for energy efficient retrofitting of residential buildings. Energy Build 2013;64:123-31.

[8] Mehmet AA, Büyükalaca O, Tuncay Y. A case study for influence of building thermal Insulation on cooling loadand air-conditioning system in the hot and humid regions. Appl Energy 2010;87:599-607.

[9] Nematchoua MK, Tchinda R, José AO. Thermal comfort and energyconsumption in modernversus traditional buildings in Cameroon: a questionnairebased statistical study. Appl Energy 2014;114:687-99.

[10] Ghrab-Morcos N. CHEOPS: a simplified tool for thermal assessment of Mediterranean residential buildings in hot and cold seasons. Energy Build 2005:37:651-62.

[11] Aïssani A, Chateauneuf A, Fontaine J-P, Audebert Ph. Cost model for optimum thicknesses of insulated walls considering indirect impacts and uncertainties. Energy Build 2014:84:21-32.

[12] Kalyon M, Sahin AZ. Application of optimal control theory in pipe insulation. Numer Heat Transf Part A 2002;41:391-402.

[13] Dragan C, Milorad B. Optimization of thermal insulation of a house heated by using radiant panels. Energy Build 2014:85:329-36.

[14] Farshid B, Dodoo A, Gustavsson L. Cost-optimum analysis of building fabric renovation in a Swedish multi-story residential building. Energy Build 2014:84:662-73.

[15] Özden A, Özgür A, Hakan D, İsmail T. Environmental impact of optimum insulation thickness in buildings. In: World Renewable Energy Congress Sweden; 8-13 May.

[16] Ucar A, Balo F. Determination of environmental impact and optimum thickness of insulation for building walls. Environmental Progress \& Sustainable Energy 2011;30:709-19.

[17] Mi Subhash, Usmani JA, Bhagman S. Study on energy saving in residential building using life cycle cost analysis. Int J Eng Math Sci 2013;4:8-17.

[18] Bojic M, Loveday DL. The influence on building thermal behavior of the insulation masonry distribution in a three-layered construction. Energy Build 1997:26:153-7.

[19] Moghimi S, Bakhtyar B, Azizpour F, Sopian K, Lim CH, Mat S, et al. Maximization of energy saving and minimization of insulation cost in a tropical hospital: a case study in Malaysia. WSEAS Trans Environ Dev 2013;9: 105-115.
[20] Bakhtyar B, Sopian K, Zaharim A, Saadatian O. The effets of feed in tariff on foreign direct investment in Malaysia. Therm Eng Environ 2012

[21] Kaynakli O. A review of the economical and optimum thermal insulation thickness for building applications. Renew Sustain Energy Rev 2012;16: $415-25$.

[22] Al-Khawaja MJ. Determination and selecting the optimum thickness of insulation for buildings in hot countries by accounting for solar radiation. Appl Therm Eng 2004;24:2601-10.

[23] Ansari FA, Mokhtar AS, Abbas KA, Adam NMA. Simple approach for building cooling load estimation. Am J Environ Sci 2005;1(3):209-12.

[24] Al-Homoud MS. Performance characteristics and practical applications of common building thermal insulation materials. Build Environ 2005;40:353-66.

[25] Yu J, Yang C, Tian L, Liao D. A study on optimum insulation thicknesses of external walls in hot summer and cold winter zone of China. Appl Energy 2009;86:2520-9.

[26] Hasan A. Optimizing insulation thickness for buildings using life cycle cost. Appl Energy 1999;63:115-24.

[27] Kaynakli O. A study of residential heating energy requirement and optimum insulation thickness. Renew Energy 2008;33:1164-72.

[28] International Energy Agency. Promoting energy efficiency investments: case studies in the residential sector. Information paper; 2008.

[29] Kolaitis DI, Malliotakis E, Kontogeorgos DA, Mandilaras I, Katsourinis DI, Founti MA. Comparative assessment of internal and external thermal insulation systems for energy efficient retrofitting of residential buildings. Energy Build 2013;64:123-31.

[30] Sanea SA, Zedan MF. Improving thermal performance of buildings wall by optimizing insulation layer distribution and thickness for same thermal mass. Appl Energy 2011;88:3113-24.

[31] Spitz C, Mora L, Wurtz E, Jay A. Practical application of uncertainty analysis and sensitivity analysis on an experimental house. Energy Build 2012;55: 459-470.

[32] Ozel M, Pihtili K. Optimum location and distribution of insulation layers on building walls with various orientations. Build Environ 2007;42:3051-9.

[33] Cenk O. Determination of the thermal insulation for the model building approach and the global effects in Turkey. Adv Mech Eng 2014:)1-13.

[34] Meral O. Cost analysis for optimum thicknesses and environmental impacts of different insulation materials. Energy Build 2012;49:552-9.

[35] Eben Saleh MA. Impact of thermal insulation location on buildings in hot dry climates. Sol Wind Technol 1990:7:393-406.

[36] Kolaitis DI, Malliotakis E, Kontogeorgos DA, Mandilaras I, Katsourinis DI, Founti MA. Comparative assessment of internal and external thermal insulation systems for energy efficient retrofitting of residential buildings. Energy Build 2013;64:123-31.

[37] Dombayci OA, Golcu M, Pancar Y. Optimization of insulation thickness for external walls using different energy-sources. Appl Energy 2006;83:921-8.

[38] Gustafsson SI. Optimisation of insulation measures on existing buildings. Energy Build 2000;33:49-55.

[39] Comakli K, Yuksel B. Optimum insulation thickness of external walls for energy saving. Appl Therm Eng 2003;23:473-9.

[40] Sisman N, Kahya E, Aras N, Aras H. Determination of optimum insulation thicknesses of the external walls and roof (ceiling) for Turkey's different degree-day regions. Energy Policy 2007;35:5151-5.

[41] Ucar A, Balo F. Determination of the energy savings and the optimum insulation thickness in the four different insulated exterior walls. Renew Energy 2010;35(1):88-94.

[42] Mahlia TMI, Taufiq BN, Ismail, Masjuki HH. Correlation between thermal conductivity and the thickness of selected insulation materials for building wall. Energy Build 2007;39:182-7.

[43] Soylemez MS, Unsal M. Optimum insulation thickness for refrigeration applications. Energy Convers Manag 1999;40:13-21.

[44] Ucar A, Balo F. Effect of fuel type on the optimum thickness of selected insulation materials for the four different climatic regions of Turkey. Appl Energy 2009;86:730-6.

[45] Bolatturk A. Optimum insulation thicknesses for building walls with respect to cooling and heating degree-hours in the warmest zone of Turkey. Build Environ 2008;43(6):1055-64.

[46] Nellis G, Klein S. Heat transfer. In: Appendix A5: introduction to economics. USA: Cambridge University Press; 2009, pp. 1-8.

[47] Daouas N, Hassen Z, Ben Aissia H. Analytical periodic solution for the study of thermal performance and optimum insulation thickness of building walls in Tunisia. Appl Therm Eng 2010:30:319-26.

[48] Meral O. Effect of wall orientation on the optimum insulation thickness by using a dynamic method. Appl Energy 2011;1(7).

[49] Sebaii AA, Hazmi FS, Ghamdi AA, Yaghmour SJ. Global, direct and diffuse solar radiation on horizontal and tilted surfaces in Jeddah, Saudi Arabia. Appl Energy 2010;87:568-76.

[50] Nielsen TR, Peuhkuri R, Weitzmann P, Gudum C. Modeling Building Physics in Simulink 2002:2-15 http://www.ibpt.org accessed 29 September 2014.

[51] Safeeq M, Fares A. Accuracy evaluation of ClimGen weather generator and daily to hourly disaggregation methods in tropical conditions. Theor Appl Climatol 2011;106:321-41.

[52] Sanea SA, Zedan MF. Optimum insulation thickness for building walls in a hot-dry climate. Int J Ambient Energy 2002;23(3):115-26.

[53] SODA. Solar energy services for professionals. HelioClim Solar radiation data, consulting; September 19th 2014. 
[54] Basunia M, Yoshio H, Abec T. Simulation of solar radiation incident on horizontal and inclined surfaces. J Eng Res 2012;9(2):27-35.

[55] Ozkan DB, Onan C. Optimization of insulation thickness for different glazing areas in buildings for various climatic regions in Turkey. Appl Energy 2011;88:1331-42.

[56] Zhou S, Zhao J. Optimum combinations of building envelop energy saving technologies for offices buildings in different climatic regions of China. Energy Build 2013;57:103-9.

[57] Agham Rahul D. State of the art insulation materials: a review. Int J Eng Innovative Technol 2012;2:97-102.

[58] Abdou AA, Budaiwi IM. Comparison of thermal conductivity measurements of building insulation materials under various operating temperatures. J Build Phys 2005;29(2):171-85.

[59] Budaiwi I, Abdou A, Al-Homoud M. Variations of thermal conductivity of insulation materials under different operating temperatures: impact on envelope-induced cooling load. J Arch Eng 2002;8(4):125-32.
[60] Choi GS, Kanga JS, Jeong YS, Lee SE, Sohn JY. An experimental study on thermal properties of composite insulation. Thermochim Acta 2007:455:75-9.

[61] Anastaselos D, Giama E, Papadopoulos AM. An assessment tool for the energy, economic and environmental evaluation of thermal insulation solutions. Energy Build 2009;41:1165-71.

[62] Papadopoulos AM. State of the art in thermal insulation materials and aims for future developments. Energy Build 2005;37:77-86.

[63] Lollini, Barozzi, Fasano, Meroni, Zinzi. Optimisation of opaque components of the building envelope. Energy, economic and environmental issues. Build Environ 2006;41:1001-13.

[64] Mahlia TMI, Taufiq BN, Ismail, Masjuki HH. Correlation between thermal conductivity and the thickness of selected insulation materials for building wall. Energy Build 2007;39:182-7.

[65] Al-Homoud MS. Performance characteristics and practical applications of common building thermal insulation materials. Build Environ 2005;40:353-66. 